\title{
Formation of Ordered Mesostructured Silica by Vapor Infiltration of Tetraethoxysilane into Hexagonally Arranged Surfactant-Catalyst Nanocomposites
}

\author{
Shunsuke Tanaka, Takanori Maruo, Norikazu Nishiyama, ${ }^{*}$ Yasuyuki Egashira, and Korekazu Ueyama \\ Division of Chemical Engineering, Graduate School of Engineering Science, Osaka University, \\ 1-3 Machikaneyama, Toyonaka, Osaka 560-8531
}

(Received May 13, 2005; CL-050638)

Hexagonally arranged surfactant-catalyst composites were treated only with tetraethoxysilane vapor, resulting in the formation of the silica mesostructures without phase transition.

Syntheses of ordered mesoporous silicas require surfactant templates which form lyotropic liquid crystal phases in the solvent (usually water) and silicate species interacts with the surfactant and polymerizes to form a silica network encapsulating the surfactant micelles. ${ }^{1}$

For a large range of applications such as low- $k$ insulators, ${ }^{2}$ antireflective coatings, ${ }^{3}$ and optical sensors, ${ }^{4}$ it would be desirable to produce mesoporous silicas in the form of thin films. Fabrication of thin films made of mesoporous silicas has conventionally been performed by liquid deposition methods such as epitaxial growth ${ }^{5}$ or sol-gel method. ${ }^{6,7}$ Self-assembled surfactant-silicate composites are deposited from a liquid phase under acidic or basic conditions.

On the other hand, we have reported a novel synthetic route of mesoporous silica films from vapor phase. ${ }^{8}$ Spin-on surfactant films were treated with tetraethoxysilane (TEOS) and hydrochloric acid $(\mathrm{HCl})$ vapors in a closed vessel. Surfactant-silicate composites were rearranged from lamer to hexagonal structure under vapor infiltration. ${ }^{8 \mathrm{a}} \mathrm{A}$ drawback of the previous method is difficulty adjusting to a continuous vapor flow system because it is unavoidable that the TEOS/ $\mathrm{HCl}$ vapor reacts and produces silicate particles not only on the film but also in gas phase.

Here, we report an advanced vapor phase synthesis of mesoporous silica films using surfactant-catalyst composites. The objective of the present study is to prepare mesoporous silica films using only TEOS in vapor phase. Thus, the catalyst should be present in the surfactant film. Nonvolatile acids such as sulfuric acid $\left(\mathrm{H}_{2} \mathrm{SO}_{4}\right)$ and phosphoric acid $\left(\mathrm{H}_{3} \mathrm{PO}_{4}\right)$ must be a candidate as a catalyst instead of a volatile acid, $\mathrm{HCl}$. Further, a novel phenomenon of the formation of surfactant-catalyst nanocomposite is presented here.

First, we have performed vapor phase synthesis in a batch reactor using surfactant films containing different catalysts, such as $\mathrm{H}_{2} \mathrm{SO}_{4}, \mathrm{H}_{3} \mathrm{PO}_{4}, \mathrm{HCl}$, and acetic acid $\left(\mathrm{CH}_{3} \mathrm{COOH}\right)$. Cetyltrimethylammonium bromide (CTAB) was used as a surfactant. The detailed synthesis and characterization methods are shown in the references and notes section. ${ }^{9}$

Figure 1a shows the XRD pattern of the spin-on film prepared using CTAB and $\mathrm{H}_{2} \mathrm{SO}_{4}$. The XRD pattern has two reflection peaks, indicating that the (100) family of planes of the hexagonal unit cell $(d=4.5 \mathrm{~nm})$ is oriented parallel to the surface of the substrate. The $\mathrm{CTAB} / \mathrm{H}_{2} \mathrm{SO}_{4}$ nanocomposite already has a hexagonal structure even before the TEOS vapor treatment. For reference, we prepared spin-on films using CTAB and volatile acid such as $\mathrm{HCl}$ or $\mathrm{CH}_{3} \mathrm{COOH}$. The films have a lamellar

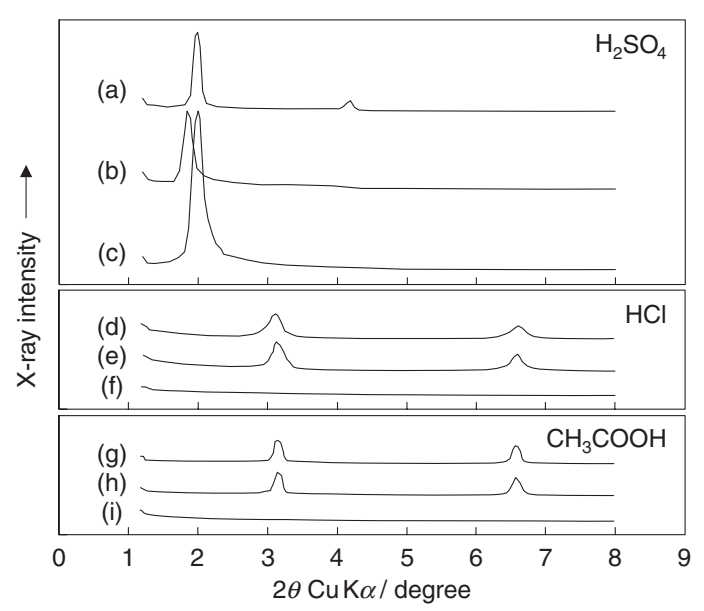

Figure 1. XRD patterns of the mesostructured films using $\mathrm{H}_{2} \mathrm{SO}_{4}, \mathrm{HCl}$, or $\mathrm{CH}_{3} \mathrm{COOH}$ as a catalyst. Traces (a), (d), and (g) show the spin-on surfactant films; Traces (b), (e), and (h) show the surfactant films treated with TEOS vapor in a batch reactor; Traces (c), (f), and (i) show the films after calcination.

structure with $d=2.8 \mathrm{~nm}$ (Figures $1 \mathrm{~d}$ and $1 \mathrm{~g}$ ). We consider that a large amount of $\mathrm{H}_{3} \mathrm{O}^{+}$and $\mathrm{SO}_{4}{ }^{-}$could adsorb on the hydrophilic head of CTAB molecules. The bulky head of surfactants caused an arrangement of the $\mathrm{H}_{2} \mathrm{SO}_{4} / \mathrm{CTAB}$ composite into hexagonal symmetry. After contacting the CTAB $/ \mathrm{H}_{2} \mathrm{SO}_{4}$ composite film with TEOS vapor using the batch reactor, the reflection peak was slightly shifted to lower angle (Figure 1b). The periodic structure swelled by $8 \%$. It is confirmed by FTIR measurement that silica network was formed on the substrate after contacting with TEOS vapor. This result indicates that TEOS molecules penetrate into the $\mathrm{CTAB} / \mathrm{H}_{2} \mathrm{SO}_{4}$ composite film. The hexagonal structure of the $\mathrm{CTAB} / \mathrm{H}_{2} \mathrm{SO}_{4}$ composite was retained after the infiltration of TEOS vapor. The periodic distance shrunk by $8 \%$ in a direction perpendicular to the surface of the substrate after calcination (Figure 1c). FTIR measurements showed that the surfactant molecules were removed from the composite. Moreover, EDX measurements showed that the calcined films were free of sulfur. On the other hand, in the case of using volatile acids, $\mathrm{HCl}$ and $\mathrm{CH}_{3} \mathrm{COOH}$, hexagonal structure did not formed (Figures $1 \mathrm{e}$ and $1 \mathrm{~h}$ ). There is no periodic structure in the calcined samples indicating that TEOS did not infiltrate into CTAB films prepared using volatile acid (Figures $1 \mathrm{f}$ and 1i).

A similar hexagonal structure was obtained when CTAB/ $\mathrm{H}_{3} \mathrm{PO}_{4}$ composite films were used. Unlike in the case of $\mathrm{H}_{2} \mathrm{SO}_{4}$, the framework included the phosphate compound even after calcination. The molar ratio of $\mathrm{P} / \mathrm{Si}$ in the calcined $\mathrm{SiO}_{2} / \mathrm{P}_{2} \mathrm{O}_{5}$ film was determined to be about 0.4 by an EDX analysis. Figure 2 


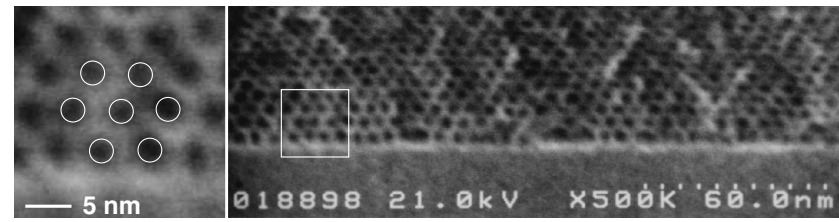

Figure 2. FE-SEM image of a cross section of the mesoporous film prepared using a spin-on $\mathrm{CTAB} / \mathrm{H}_{3} \mathrm{PO}_{4}$ film.

shows the FE-SEM image of a cross section of the calcined silica film. Periodic mesostructures were clearly observed around the surface of the substrate, with uniform pores $(3.0 \mathrm{~nm})$, indicating that diffusion of TEOS molecules is so fast that the TEOS molecules penetrate to the $\mathrm{H}_{3} \mathrm{PO}_{4} / \mathrm{CTAB}$ film-substrate interface. The distance from layer to layer is about $3.8 \mathrm{~nm}$, which is consistent with the result of the XRD measurements (see Supplementary Information Figure S1).

We proposed a surfactant-catalyst templating model for a formation of the mesostructured silica film in Figure 3. A spin-on surfactant-catalyst film has a hexagonal structure already. TEOS molecules penetrate into a hydrophilic $\mathrm{H}_{2} \mathrm{O}$ / catalyst part around the CTAB molecules without nano phase transition.

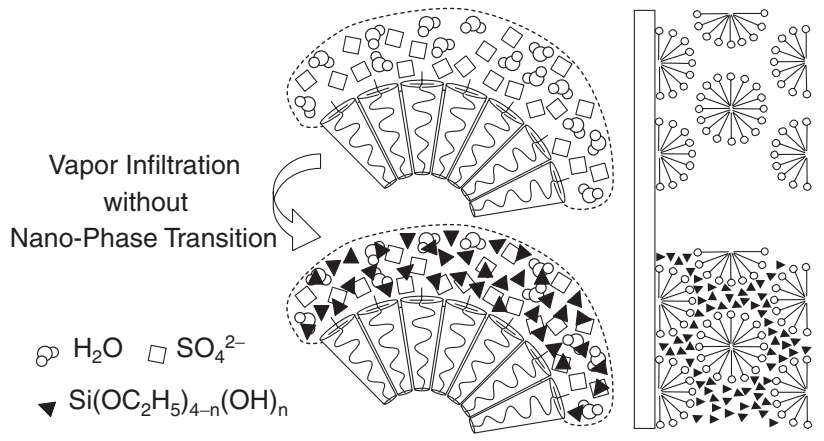

Figure 3. Proposed surfactant-catalyst templating model for a formation of ordered mesostructured silica film.

Next, this technique was applied to a continuous vapor flow system at atmospheric pressure. In a continuous flow synthesis, surfactant films were exposed to a TEOS vapor using a tubular reactor (see Supplementary Information Figure S2). The detailed synthesis method is shown in the references and notes section. ${ }^{10}$

Figure 4 shows XRD patterns of the mesostructured silica films prepared under a continuous TEOS vapor flow. TEOS molecules penetrate into the $\mathrm{CTAB} / \mathrm{H}_{2} \mathrm{SO}_{4}$ composite film with-

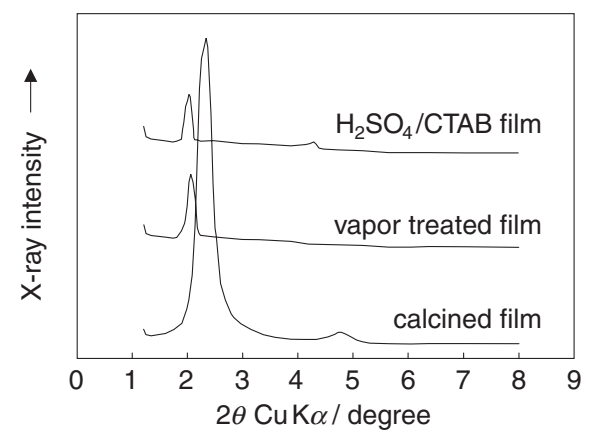

Figure 4. XRD patterns of the mesostructured films prepared under continuous vapor flow of TEOS. out phase transition. The periodic mesostructures of the films were retained after calcination although the structural contractions were observed under heating. The film thickness was about $400 \mathrm{~nm}$. On the other hand, the continuous flow synthesis using the volatile acids such as $\mathrm{HCl}$ and $\mathrm{CH}_{3} \mathrm{COOH}$ was impossible.

The continuous vapor phase synthesis is expected to be a useful technique for mass production. In addition, the formation of mesostructured silica without phase transition is a simpler way than the previous method for the control of the structure orientation.

We gratefully acknowledge the assistance of the GHAS laboratory and Mr. M. Kawashima at Osaka University with the FE-SEM measurements.

\section{References and Notes}

1 C. T. Kresge, M. E. Leonowicz, W. J. Roth, J. C. Vartuli, and J. S. Beck, Nature, 359, 710 (1992); J. S. Beck, J. C. Vartuli, W. J. Roth, M. E. Leonowicz, C. T. Kresge, K. D. Schmidtt, C. T. W. Chu, D. H. Olson, E. W. Sheppard, S. B. McCullen, J. B. Higgins, and J. L. Schlenker, J. Am. Chem. Soc., 114, 10834 (1992).

2 C. M. Yang, A. T. Cho, F. M. Pan, T. G. Tsai, and K. J. Chao, Adv. Mater., 13, 1099 (2001).

3 P. Falcaro, D. Grosso, H. Amenitsch, and P. Innocenzi, J. Phys. Chem. B, 108, 10942 (2004).

4 S. Subbiah and R. Mokaya, Chem. Commun., 2003, 860.

5 I. A. Aksay, M. Trau, S. Manne, I. Honma, N. Yao, L. Zhou, P. Fenter, P. M. Eisenberger, and S. M. Gruner, Science, 273, 892 (1996).

6 M. Ogawa, J. Am. Chem. Soc., 116, 7941 (1994).

7 Y. Lu, R. Ganguli, C. A. Drewien, M. T. Anderson, C. J. Brinker, W. Gong, Y. Guo, H. Soyez, B. Dunn, M. H. Huang, and J. I. Zink, Nature, 389, 364 (1997).

8 a) N. Nishiyama, S. Tanaka, Y. Egashira, Y. Oku, and K. Ueyama, Chem. Mater., 15, 1006 (2003). b) S. Tanaka, N. Nishiyama, Y. Oku, Y. Egashira, and K. Ueyama, J. Am. Chem. Soc., 126, 4854 (2004). c) S. Tanaka, N. Nishiyama, Y. Hayashi, Y. Egashira, and K. Ueyama, Chem. Lett., 33, 1408 (2004).

9 A coating solution was prepared using surfactant, catalyst, $\mathrm{EtOH}$, and deionized water with the mole ratios of 0.5:0.9: 50:100 surfactant/catalyst/EtOH/ $\mathrm{H}_{2} \mathrm{O}$. The mixture was dropped onto the silicon substrate while it was spinning at $50 \mathrm{rpm}$, and then the substrate spin up to $4000 \mathrm{rpm}$ for $60 \mathrm{~s}$. The surfactant films were treated only with TEOS in a batch reactor as follows. The surfactant-coated silicon substrate was arranged to lie vertically in a closed vessel $\left(50 \mathrm{~cm}^{3}\right)$. Small amount of TEOS was placed in the bottom of the vessel apart from the substrate. The vessel was placed in an oven at $90^{\circ} \mathrm{C}$ for $2 \mathrm{~h}$. Calcination was performed at $400^{\circ} \mathrm{C}$ in air for $5 \mathrm{~h}$ with a heating rate of $1{ }^{\circ} \mathrm{C} / \mathrm{min}$. The films were identified by X-ray diffraction (XRD) patterns recorded on a Rigaku Mini-flex. Fourier-transform infrared (FTIR) spectra of the films were recorded using a FTIR-8200PC spectrometer (Shimadzu Co.). Field emission scanning electron microscope (FE-SEM) images were recorded on a Hitachi S-5000L microscope.

10 A tubular reactor was a horizontal quartz tube of $60-\mathrm{cm}$ length and 2-cm inner diameter surrounded by an electrical heater (ISUZU EPKRO-11K). The temperature was controlled at 90$150{ }^{\circ} \mathrm{C}$. The surfactant-coated substrate was arranged to lie horizontally in the tubular reactor. TEOS was fed with a $\mathrm{N}_{2}$ carrier gas for $3 \mathrm{~h}$. The feed rates of $\mathrm{N}_{2}$ and TEOS $/ \mathrm{N}_{2}$ were $0-30$ and $30 \mathrm{~mL} / \mathrm{min}$, respectively. The films were subsequently calcined in flowing air at $400{ }^{\circ} \mathrm{C}$ for $5 \mathrm{~h}$ to remove the surfactant. 